that afforestation would be acceptable; (b) areas where, although there is a presumption against afforestation, proposals might be acceptable; and (c) areas where there is a strong presumption against afforestation. These categories are devised as a general guide to policy and should be adjusted where necessary to meet particular circumstances. The surveys are intended to be discussed between the planning authorities, the National Parks Commission and the other parties to the agreement. The Forestry Commission has promised to frame its afforestation proposals in accordance with the surveys, amended as necessary after these consultations, and it is hoped that private landowners will do likewise. The arrangements will not apply outside national parks, nor to the replanting of existing woodlands. The agreement does not refer to the character or type of afforestation.

\section{Radioactive Materials in Food and Agriculture}

Although the references quoted in the recent report of a Food and Agriculture Organization Expert Committee, entitled Radioactive Materials in Food and Agriculture, and the contaminationlevels available to the Committee were no more recent than 1958, and there are still wide gaps in our information, the publication represents a valuable balanced and readable general survey of the subject, and one which lays stress on basic concepts $(\mathrm{Pp}$. ix + 123. Rome: Food and Agriculture Organization of the United Nations. London: H.M. Stationery Office, $1960.7 s .6 d . ; 1.50$ dollars). Radionuclides enter the human body, primarily via the food chain, along which a great many environmental variables can modify the contamination of the final food product. Some emphasis has been placed here on matters of soil and plant contamination, but attention is given to animal products, food processing, marine biology, human dietary aspects and overall survey and sampling problems. Although the predominant man-produced contamination of our environment with radionuclides on a world-wide scale has its origin in nuclear explosions, effluents from nuclear power-plant can be a factor of local importance. Some attention is directed to the ability of some marine forms to concentrate certain radionuclides one-hundred-fold from the sea, and to a feasible method for decontaminating milk supplies in an emergency. The Committee makes important recommendations which specify those particular fields where further research and survey work are most urgently needed. It is perhaps as well that the few orrors which occur in the text so greatly alter the sense of the passage that they are easily detected for exarnple, on page 41, environmental carbon-14 does not amount to approximately 10-11 per cent of carbon-12.

\section{Origin and Evolution of Coal}

The Geological Survey and Museum has published a 17-page pamphlet entitled The Origin and Evolution of Coal (Department of Scientific and Industrial Research. By Dr. P. J. Adams. Pp. i 17. (London : H.M. Stationery Office, 1960.) 1s. 9d. net); this is substantially a reprint of an article that appeared in the Fuel Economy Review of 1955. Starting from the definition of coal as "a combustible rock which had its origin in the accumulation and partial decomposition of vegetation", it traces the history of the different vegetablo ingredients that went towards the formation of coal, first through their biochemical decomposition to peat and sapropel (slimy sediment), and later through physical and chemical changes brought about by temperature and pressure during the course of the burial of peat and sapropel to greater depth. The familiar 'humic' coals, assumed to be derived from peat, together with their constituent macerals, and the sapropelic coals (cannel and boghead), are then described. Following a brief discussion of the part played in these processes by crustal movement, the lignite-anthracite series is discussed with reference to the progressive chemical changes involved. Finally, the geological record of coal formation is summarized in a useful table. Begun about 300 million years ago, this process still continues, though in small measure: for example, in the Everglades of Florida. It is thought possible that natural graphite might be derived from still earlier coals. This booklet should prove helpful to those requiring a concise picture of cosl geology, for use in lecturing and teaching.

\section{Labelling of Medicinal Preparations}

A memorandum giving guidance on the procedure to be followed in devising labels and titles for com. pounded medicinal preparations has been issued by the Association of British Pharmaceutical Industry, the Proprietary Association of Great Britain and the Association of Public Analysts (Labelling Procedure for Compounded Medicinal Preparations. Pp. 6. London : Association of British Pharmaceutical Industry, 1960). Section 6 of the Food and Drugs Act, 1955, enacts certain requirements with regard to the labelling of food and drugs. When considering the provisions of the Act practitioners realize that the attitude of the public to the purchase of medicinal preparations is not necessarily identical with their approach to the purchase of food. Consequently, it may be desirable to apply to medicinal preparations labelling requirements comparable with those introduced for food by Statutory Orders and Instruments. Further, the law does not impose on medicinal preparations labelling requirements comparable with those introduced for food. The memorandum gives detailed recommendations for labelling as well as definitions of the compounds affected.

\section{Nuclear Fusion: Journal of Plasma Physics and Thermonuclear Fusion}

IT is natural, though not necessarily pleasing, that the increased interest in the physics of ionized gases should lead to the appearance of specialist journals dealing with recent developments in that subject. Nuclear Fusion, subtitled Journal of Plasma Physics and Thermonuclear Fusion, which will probably be preoccupied for some time with the former subject, is the latest addition (1, No. 1 (September 1960). Pp. 68. Published quarterly. (Vienna: International Atomic Energy Agency, 1960.) Annual subscription 250 Schillings ; 70s. ; 10 dollars. Single issues 75 Schillings; $21 s$. 3 dollars). It is a wellproduced journal, with photographs and diegrams accompanying the toxt, although the advantage of two-column printing in a subject so mathematical as to require frequent whole-width displayed formulæ is obscure. The material in the first issue, which is of high quality, consists of the first part of a leisurely and complete survey of the oscillations of $a_{0}$ plasma, a highly mathematical discussion of the stability of an axially symmetric plasma, a brief note on the energy distribution of thermonuclear neutrons, 